D

${ }^{1}$ Academic Medical Center, University of Amsterdam, Dept of Respiratory Medicine and

Dept of Intensive Care, Amsterdam, The Netherlands.

${ }^{2} \mathrm{KU}$ Leuven-University of Leuven, Faculty of Kinesiology and Rehabilitation Sciences, Dept of

Rehabilitation Sciences, Research Group for Cardiovascular and Respiratory Rehabilitation,

Leuven, Belgium.

${ }^{3}$ Respiratory and Sleep Diagnostics Dept, Regional Hospital Mullingar, Mullingar, Ireland.

\title{
New ECMC members
}

\section{Early Career Forum}

\section{A message from the newly elected ECMC Chair, Lieuwe Bos}

I would like to introduce myself as the new chair of the Early Career Member Committee (ECMC). My name is Lieuwe Bos and I'm situated in Amsterdam, the Netherlands, where I also defended my PhD thesis under supervision of Prof. Peter Sterk (respiratory medicine) and Prof. Marcus Schultz (intensive care). I continued my clinical training in pulmonology in Amsterdam in the group of Prof. Elisabeth Bel.

The ECMC has grown over the past year from an underground movement into a strong group of early career members who loudly and clearly echo the needs of junior members in the society. I would like to continue that upward trend. My background in clinical work, teaching and research will help me to identify with the key aspects of the European Respiratory Society (ERS). Over the past years, I have worked in several collaborative European projects. During that period, I learned a lot about organising and leading meetings with many people from different countries and backgrounds. It also provided insight into the stringent rules of European projects. I also love to give talks and interact with young researchers. In my spare time, I try to swim, cycle and run as much as possible to stay fit for triathlons in the summer season.
In order to continue the upward trend for Early Career Member involvement in the ERS, there will be several challenges in the coming years. A regular challenge is to organise sessions for the International Congress. We will find young people to talk about personal choices and decisions that can inspire us all in our research. All sessions should to be gender equal, preferably not involving the "usual suspects". This focus should also be reflected in the other activities. The ECMC members should be as approachable as possible. Anyone can speak to us at conferences, where we will clearly identify ourselves. All motivated Early Career Members can be involved in ERS activities; as reviewers, as co-chairs, as applicants for fellowships or as contributors to Breathe.

The ECMC is always looking for young researchers (age $<40$ years) who would like to get involved in the society. Join to let us know your interests; you could be asked to write an article for Breathe, chair a session at the International Congress or submit a grant application for a fellowship. Please find us in person at Congress or through our website (juniors.ersnet.org), or join us at ResearchGate by following one of the ECMC members and joining our projects

\section{Early Career Member Committee}

The ECMC has several new members who have joined since the International Congress in London.
Cite as: Bos LD, Langer D, Flood E. New ECMC members. Breathe 2017; 13: 51-52. 
Contact your representative if you want to get more involved within the ECMC:

- Clinical Nicolas Kahn

- Respiratory Intensive Care Lieuwe Bos

- Cell and Molecular Biology Sabine Bartel

- Clinical Physiology, Sleep and Pulmonary Circulation Isaac Almendros

- Airway Diseases Alexander G. Mathioudakis

- Occupation and Epidemiology Ane Aamli

- Paediatrics Raffaella Nenna

- Thoracic Surgery and Transplantation Elodie Lhuillier

- Allied Respiratory Professionals Emma Flood

- Respiratory Infections Aran Singanayagam

- Thoracic Oncology Nina Bostantzoglou

\section{Opportunities for Early Career Members: RESPIRE3}

RESPIRE3 is an international, intersectoral and interdisciplinary programme providing Marie Skłodowska-Curie post-doctoral research fellowships to early-stage scientists with the potential to become the leaders of tomorrow in the respiratory field. The RESPIRE3 programme offers 2-year European and 3-year global fellowships.

\section{Key eligibility criteria}

- Candidates from any discipline (e.g. life sciences, medicine, engineering, mathematics, information technology, etc.) are highly encouraged to apply with a research proposal related to respiratory science, in line with the ERS Roadmap (www.ersroadmap.org).

- Experienced researcher: at the time of the call deadline for the recruitment of researchers (e.g. March 1, 2017 for first call), applicants must be in possession of a doctoral degree or have at least 4 years of full-time, equivalent research experience.

- Marie Skłodowska-Curie mobility rule: at the time of the call deadline for the recruitment of researchers (e.g. March 1, 2017 for the first call), applicants must demonstrate transnational mobility and must not have resided or carried out their main activity in the country of the host centre for more than 12 months in the 3 years immediately prior to the reference date.

- Publications: applicants must have at least one first-author (or co-first author) paper published (or accepted for publication) in an international, peer-reviewed journal by the call deadline.

- There shall be no double funding, or any concurrent combination of a RESPIRE3 fellowship with any other Marie SkłodowskaCurie Actions funding or any funding by other bodies. Past RESPIRE1 or RESPIRE2 fellows are not eligible. Researchers that are already permanently employed by the host entity where the RESPIRE3 research training activities are planned may not be supported.

\section{Conflict of interest}

None declared. 